\title{
On the value of water quality data and informative flow states in karst modelling
}

\author{
Andreas Hartmann ${ }^{1,2}$, Juan Antonio Barberá ${ }^{3}$, and Bartolomé Andreo ${ }^{3}$ \\ ${ }^{1}$ Faculty of Environment and Natural Resources, University of Freiburg, Freiburg, Germany \\ ${ }^{2}$ Department of Civil Engineering, University of Bristol, Bristol, UK \\ ${ }^{3}$ Department of Geology and Centre of Hydrogeology, University of Malaga (CEHIUMA), Malaga 29071, Spain
}

Correspondence to: Andreas Hartmann (andreas.hartmann@hydrology.uni-freiburg.de)

Received: 18 April 2017 - Discussion started: 10 May 2017

Revised: 11 October 2017 - Accepted: 12 October 2017 - Published: 30 November 2017

\begin{abstract}
If properly applied, karst hydrological models are a valuable tool for karst water resource management. If they are able to reproduce the relevant flow and storage processes of a karst system, they can be used for prediction of water resource availability when climate or land use are expected to change. A common challenge to apply karst simulation models is the limited availability of observations to identify their model parameters. In this study, we quantify the value of information when water quality data $\left(\mathrm{NO}_{3}^{-}\right.$and $\left.\mathrm{SO}_{4}^{2-}\right)$ is used in addition to discharge observations to estimate the parameters of a process-based karst simulation model at a test site in southern Spain. We use a three-step procedure to (1) confine an initial sample of 500000 model parameter sets by discharge and water quality observations, (2) identify alterations of model parameter distributions through the confinement, and (3) quantify the strength of the confinement for the model parameters. We repeat this procedure for flow states, for which the system discharge is controlled by the unsaturated zone, the saturated zone, and the entire time period including times when the spring is influenced by a nearby river. Our results indicate that $\mathrm{NO}_{3}^{-}$provides the most information to identify the model parameters controlling soil and epikarst dynamics during the unsaturated flow state. During the saturated flow state, $\mathrm{SO}_{4}^{2-}$ and discharge observations provide the best information to identify the model parameters related to groundwater processes. We found reduced parameter identifiability when the entire time period is used as the river influence disturbs parameter estimation. We finally show that most reliable simulations are obtained when a combination of discharge and water quality date is used for the combined unsaturated and saturated flow states.
\end{abstract}

\section{Introduction}

It is estimated that around 10-15\% of emerged Earth surface is covered by soluble rocks that are susceptible to be karstified (Ford and Williams, 2007). Today, aquifers developed in such types of rock roughly supply groundwater to a quarter of the world's population. The importance of groundwater resources from karst aquifers is not only limited to satisfy the fresh water demand of large regions with millions of inhabitants (e.g. Austria or Slovenia) but also it guarantees the water supply in small settlements where karst waters are the only source of drinking water.

The intrinsic characteristics of karst aquifers such as the development of a secondary porosity through enlarged conduits and fractures, as well as the duality of the recharge (diffuse vs. concentrated), result in a high-permeability media (Bakalowicz, 2005; White and White, 2003). The shallower parts of the aquifers, including soil and epikarst (i.e. unsaturated zone), play a key role in the understanding of system functioning. Epikarst is characterized by slow percolation of air and water into narrow fissures, inducing water storage, and by a rapid drainage through a connected conduit system promoting flow concentration (Aquilina et al., 2006; Ford and Williams, 2007; Labat et al., 2000). Thus, in the top few metres of aquifer rock, biogeochemical processes occur in a multiphase environment (gas, liquid, and solid) and recharge waters rapidly acquire their chemical composition, remaining practically unaltered until they reach the emergence points. Rapid drainage deters that such a physicochemical processes may dissipate naturally a potential contaminant entering into the system. Therefore, karst aquifers are especially vulnerable to contamination despite the fact 
that the unsaturated zone, jointly with soil and epikarst, acts chemically as a reaction layer that is able to modify the groundwater quality in a substantial way.

Simulation models are a common tool to address water management questions such as the impacts of climate and land use changes on karst water resources (Hartmann et al., 2014a). In order to provide reliable predictions, these models need to include the most relevant processes of karst systems and various approaches have been developed to include karst processes in distributed and lumped karst simulation models (Ghasemizadeh et al., 2012; Hartmann et al., 2014a; Hartmann and Baker, 2017; Kovacs and Sauter, 2007; Sauter et al., 2006). The choice of the model approach is usually due to the required purpose. A key challenge in all of these karst modelling approaches is the identification of the model parameters. Methods to explore and analyse karst systems can provide prior knowledge on karst system properties (Goldscheider and Drew, 2007) that can be used to gain prior information on karst model parameters such as hydraulic conductivities or catchment boundaries. However, capturing the entire heterogeneity of karst systems with those methods is commonly impossible (Hartmann et al., 2013a) and inverse parameter estimation schemes, for instance automatic calibration by observed discharge, have to be applied.

Work with automatic calibration approaches showed that using only discharge observations for model calibration allows us to identify up to six model parameters (Jakeman and Hornberger, 1993; Wheater et al., 1986; Ye et al., 1997). More recent works also revealed that including disinformative periods in the calibration, i.e. periods when errors in the observation can be expected, may significantly bias the results of model calibration and evaluation of hydrological models (Beven et al., 2011; Beven and Westerberg, 2011; Kauffeldt et al., 2013). Due to the complexity of karst processes, karst models usually require more than six model parameters to reflect the most important hydrological processes. Some studies tried to compensate for this apparent lack of information by using auxiliary data such as gravimetric information (Mazzilli et al., 2012), artificial tracer experiments (Hartmann et al., 2012; Oehlmann et al., 2015), or hydrochemical information (Charlier et al., 2012; Hartmann et al., 2013b, 2016). However, to our knowledge the problem of disinformative observations, either discharge observations or auxiliary information, has not been addressed explicitly in karst modelling studies.

This study proposes a new approach to quantitatively assess the information content of discharge and hydrochemical information for karst model calibration including periods with disinformative observations. A process-based model is used to simulate the hydrodynamic and hydrochemical $\left(\mathrm{NO}_{3}^{-}\right.$ and $\mathrm{SO}_{4}^{2-}$ ) behaviour of a karst system, at which the unsaturated zone dynamics dominate under recharge conditions, controlling groundwater flow and solute transport processes. During specific periods, the discharge and chemistry of the system is influenced by the surface flow of a nearby river, which constitutes disinformative periods for model parameter estimation. A new parameter estimation approach is employed to estimate the information content of the different types of calibration data during predefined flow states that focus on time periods dominated by unsaturated zone discharge, saturated zone discharge, and periods that include the disinformative observations. Even though it is applied to only one particular study site this approach can easily be transferred to any hydrological system where different observation types are available for calibration.

\section{Study site description}

The experimental area is located in the eastern Ronda mountains, in the NW of Málaga province (southern Spain). It consists of steep and rugged NE-SW oriented reliefs (e.g. Sierra Blanquilla), reaching a maximum height of $1428 \mathrm{~m}$ a.s.l. (Viento peak; Fig. 1). Geologically, three main stratigraphic groups can be differentiated (Cruz-Sanjulián, 1974; MartínAlgarra, 1987; Fig. 1): (i) clays and evaporites of upper Triassic age (the older formation), (ii) a thick (up to $500 \mathrm{~m}$ ) carbonate sequence of Jurassic dolostones and limestones forming the main aquifer (i.e. Sierra Blanquilla), and (iii) Cretaceous-Paleogene marls and marly limestones as the uppermost materials. The geological structure of the Sierra Blanquilla is constituted by a NE-SW oriented box-shaped anticline, plunging towards NE (Martín-Algarra, 1987), with a flat and wide hinge, as well as subvertical flanks. The folded structure is also fractured by two sets of faults $50^{\circ} \mathrm{N}-70^{\circ} \mathrm{E}$ and N150E oriented (Fernández, 1980). From the point of view of the karst landscape development in plateau areas, the horizontal bedding planes of carbonate exposures together with the high precipitation rate have favoured the formation of exokarstic features including karrenfields, dolines, uvalas, shafts, and swallets, as a result of intense karstification processes.

\subsection{Karst hydrogeology}

The Sierra Blanquilla carbonate aquifer is permeable through fractures and by karstification. Recharge is mostly produced by rainwater infiltration through the carbonate exposures, although seepage from a losing river and streams also account for groundwater input (Barberá and Andreo, 2015, 2012). Natural groundwater discharge is preferentially conducted towards the SE border of the aquifer (Fig. 1), through several springs that constitute the discharge area towards the Turón river valley (Barberá, 2014). Among them, El Burgo (BG, $600 \mathrm{~m}$ a.s.l.) and Hierbabuena (HB, $645 \mathrm{~m}$ a.s.l.) perennial springs drain most of the groundwater of the hydrogeological system (Fig. 1). During high-flow periods, when the total flow of the BG and $\mathrm{HB}$ springs exceeds $1.1 \mathrm{~m}^{3} \mathrm{~s}^{-1}$, two overflow springs (Ofs-I, $655 \mathrm{~m}$ a.s.l.; and Ofs-II, $670 \mathrm{~m}$ a.s.l.), 

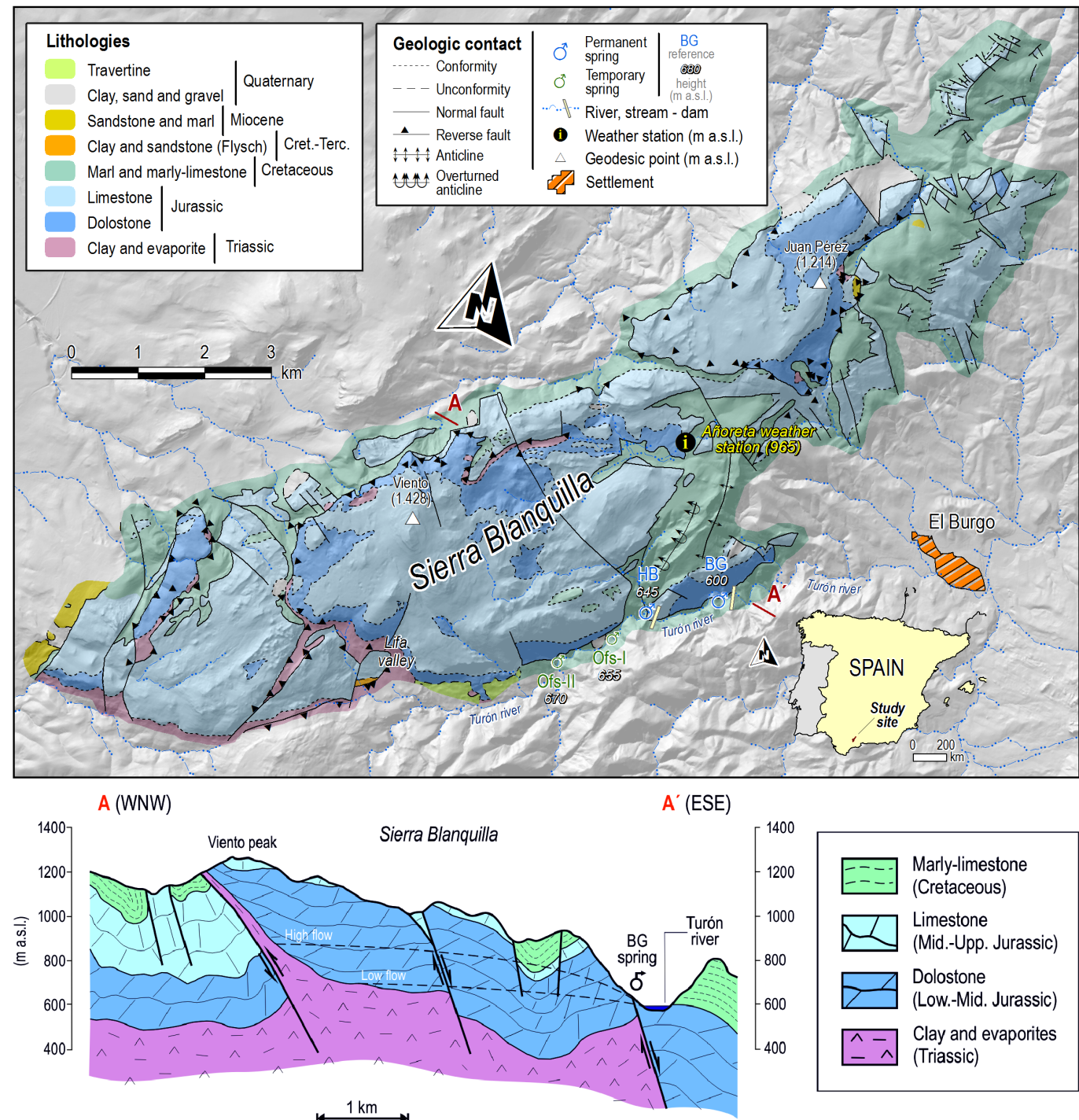

Figure 1. Geographic, geological, and hydrogeological features of the Sierra Blanquilla carbonate aquifer.

located upstream of the permanent ones, activate after heavy rainfall events (Barberá and Andreo, 2015). Low flow is established when the permanent groundwater flow (from BG and $\mathrm{HB}$ springs) is below $0.2 \mathrm{~m}^{3} \mathrm{~s}^{-1}$.

The main hydrological feature in the test site, the Turón river, intermittently crosses the carbonate exposures at the southern border of the Blanquilla aquifer (Fig. 1). The surface flow has been demonstrated to alter the hydrodynamic functioning of both perennial springs (Barberá and Andreo, 2015), which are partly affected by the existence of two regulation dams (20-25 m high) built over the Turón riverbed, just several tens of meters downstream from the springs (Fig. 1). In high-flow periods, both headwater and groundwater discharge from the Sierra Blanquilla aquifer maintain the river flow, while during low-flow conditions, the Turón river is exclusively fed by karst groundwater.

\subsection{Dominant hydrogeological processes}

Electrical conductivity (EC) has been used as a global physicochemical marker for distinguishing the hydrochemical states that characterize the El Burgo spring discharge. Generally, EC peaks seem to be concomitant with maximum spring discharge on the event scale, which is evidence that more mineralized groundwater is drained immediately after each rainfall episode (green shaded areas in Fig. 2). Barberá and Andreo (2015) stated that this high EC groundwater is also characterized by higher alkalinity and $\log P_{\mathrm{CO}_{2}}$ values and higher $\mathrm{Ca}^{2+}$ and TOC (total organic carbon) contents, suggesting the predominant limestone dissolution in the shallower parts of the aquifer. This spring behaviour reflects a functioning based on a "piston effect", by which groundwater stored in the epikarst reservoir is pulled out to the unsatu- 


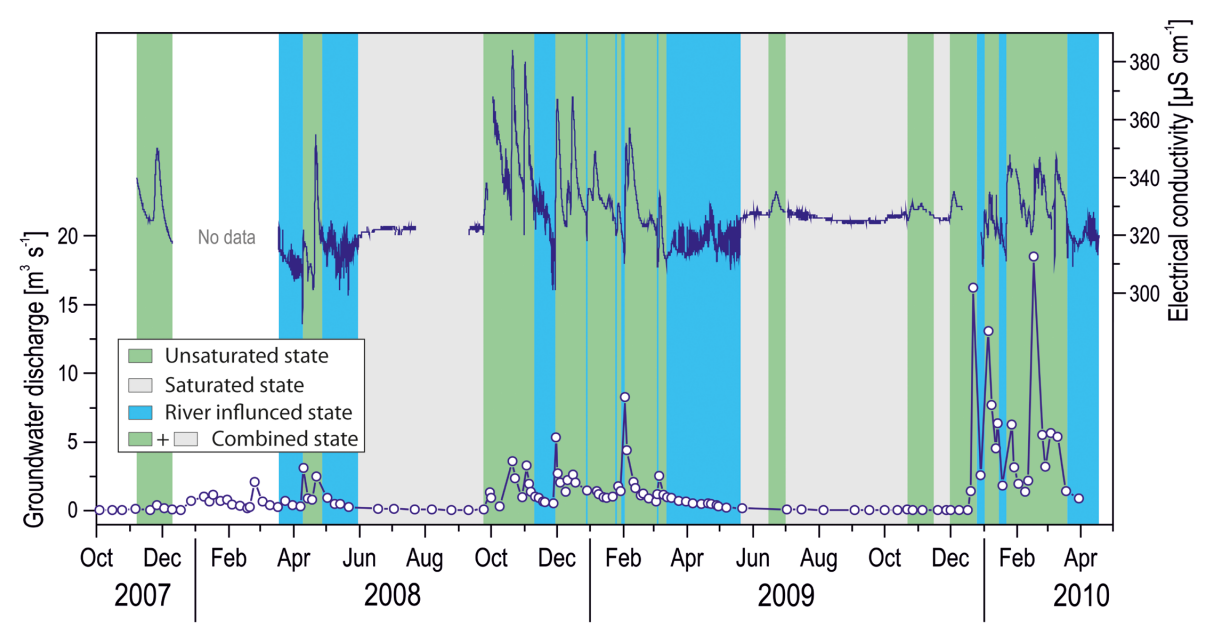

Figure 2. Decomposition of the El Burgo spring flow in selected hydrochemical states from EC and discharge time series: (1) unsaturated zone dominates discharge; (2) saturated zone dominates discharge; and (3) discharge (and EC) influenced by the Turón river flow; the combination of unsaturated and saturated states represents the combined flow state.

rated and saturated zone until the discharge zone by a subsequent recharge pulse. Therefore, unsaturated flow dominates under high-water conditions in the El Burgo spring (unsaturated state in Fig. 2).

Under low-flow conditions (no rainfall, light gray areas with data areas in Fig. 2), EC levels in the groundwater remain quite stable in the range of $320-330 \mu \mathrm{S} \mathrm{cm}^{-1}$. This provides the chemical baseline of the system (saturated state in Fig. 2), which is dependent on the accumulated rainfall on each hydrological year. The lower and less variable EC values of groundwater compared with those obtained under high-water conditions can be explained by the loss of "aggressiveness" of groundwater (degassed waters with respect to $\mathrm{CO}_{2}$ ) flowing through the system as a consequence of the lack of aquifer recharge (Barberá and Andreo, 2015). Therefore, groundwater drainage under low-water conditions consists of a system of slower flows coming from capacitive compartments of the aquifer (the phreatic zone). With these circumstances, the functioning of the hydrogeological system is mainly dominated by the saturated zone (saturated state in Fig. 2). Even though there still might be some seepage from the soil and epikarst during this stage, the hydrochemical signature of the spring, which is dominated by the signal of the phreatic zone (Barberá and Andreo, 2015), shows that these fractions are not very important.

Marked dilutions in groundwater mineralization (below the chemical baseline of the system), which very often occur during the spring recession after flood events, are also observed in the chemograph of the El Burgo spring (preferentially from March to June in Fig. 2). Since the Turón river waters are less mineralized than groundwater and that the temporary storage of surface water in the nearby river dam favours water mixing, surface water dilutes groundwater from the spring (river influenced state in Fig. 2). This occurs when the river stage is higher than the groundwater level in the discharge zone, promoting water flow towards the aquifer (Barberá and Andreo, 2015).

\section{Methodology}

\subsection{Available data}

Continuous daily measurements of precipitation and air temperature were recorded at Añoreta weather station (Fig. 1) and discrete sampling campaigns for meteoric water chemistry $\left(\mathrm{NO}_{3}^{-}\right.$and $\mathrm{SO}_{4}^{2-}$ among others) were performed in a rain collector installed to the north of Viento peak (Fig. 1), from August 2007 to April 2010. From meteorological data, potential evapotranspiration was calculated on a daily time scale using Thornthwaite's approach (Thornthwaite, 1948). Discontinuous measurements of the Turón river flow in two selected sections ( $T_{\mathrm{up}}$ and $T_{\mathrm{dn}}$ ), upstream and downstream of the permanent and temporary springs, were conducted during the same study period to quantify the net groundwater discharge from the Sierra Blanquilla aquifer. Simultaneously, a representative sampling of the chemical composition $\left(\mathrm{NO}_{3}^{-}\right.$ and $\mathrm{SO}_{4}^{2-}$ ) of karst groundwater was performed (daily to biweekly) at the El Burgo spring. Additionally, hourly data of EC were recorded at this outlet. Detailed methodological procedures can be found in Barberá and Andreo (2015). The environmental tracers $\mathrm{NO}_{3}^{-}$and $\mathrm{SO}_{4}^{2-}$ were chosen as complementary time series for the model development because they are expected to provide distinctive chemical signatures that characterize flow and transport processes in the soil and epikarst (nitrogen cycling) and saturated zone (dissolution of evaporites at the aquifer basement) of the Sierra Blanquilla aquifer. Table 1 provides a summary of all available data. In addition, the information on the three differentiated flow 
Table 1. Main characteristics of the time series of hydrodynamic and hydrochemical data used in this study. CV is the coefficient of variation.

\begin{tabular}{|c|c|c|c|c|c|c|c|c|c|}
\hline Sampling site & Parameter & Unit & $n$ & $\operatorname{Max}$ & Min & Mean & $\begin{array}{l}\mathrm{CV} \\
(\%)\end{array}$ & $\begin{array}{l}\text { Average sampling } \\
\text { frequency }\end{array}$ & Period \\
\hline \multirow[t]{2}{*}{ Añoreta weather st. } & rainfall (accumulated) & $\mathrm{mm} \mathrm{day}^{-1}$ & 959 & 71 & 0 & 3.3 & - & 1 day & $16 / 08 / 2007-31 / 03 / 2010$ \\
\hline & air temperature (daily mean) & ${ }^{\circ} \mathrm{C}$ & 959 & 14.9 & 2.6 & 8 & - & 1 day & $16 / 08 / 2007-31 / 03 / 2010$ \\
\hline \multirow[t]{2}{*}{ Viento rain collector } & $\mathrm{NO}_{3}^{-}$ & $\mathrm{mg} \mathrm{L}^{-1}$ & 38 & 23 & 0 & 3 & 2 & 15 days $*$ & 04/10/2007-16/02/2010 \\
\hline & $\mathrm{SO}_{4}^{2-}$ & $\mathrm{mg} \mathrm{L}^{-1}$ & 38 & 4.9 & 0.3 & 1.2 & 1 & 15 days $*$ & 04/10/2007-16/02/2010 \\
\hline Turón river & discharge (GW component) & $\mathrm{m}^{3} \mathrm{~s}^{-1}$ & 132 & 18.5 & 0.06 & 1.63 & 169 & 7 days & $16 / 08 / 2007-30 / 03 / 2010$ \\
\hline \multirow[t]{3}{*}{ El Burgo spring } & electrical conductivity (EC) & $\mu \mathrm{S} \mathrm{cm}^{-1}$ & 17296 & 384 & 288 & 326 & 3 & $1 \mathrm{~h}$ & 07/11/2007-15/04/2010 \\
\hline & $\mathrm{NO}_{3}^{-}$ & $\mathrm{mg} \mathrm{L}^{-1}$ & 130 & 21.2 & 0.8 & 5.1 & 56 & 8 days & $01 / 08 / 2007-30 / 03 / 2010$ \\
\hline & $\mathrm{SO}_{4}^{2-}$ & $\mathrm{mg} \mathrm{L}^{-1}$ & 130 & 24.4 & 4.2 & 11.4 & 49 & 8 days & 01/08/2007-30/03/2010 \\
\hline
\end{tabular}

* Sampling frequency was dependent on the occurrence of rainfall episodes.

states of the system (Sect. 2.2) was used to provide an independent consideration of observations that can be attributed to time periods of the unsaturated state, saturated state, and all states including the period influenced by the Turón river dynamics (river influenced state).

\subsection{The model}

The VarKarst model was previously developed at a neighbouring karst system in southern Spain (Hartmann et al., 2013b) and it was successfully applied at different karst systems around Europe (Brenner et al., 2016; Hartmann et al., 2013a, 2014b, 2016). It includes the variability of karst system properties by statistical distribution functions (Fig. 3). Explicitly, it considers the spatial variability in (i) soil and epikarst depths, (ii) fractions of concentrated and diffuse recharge to the groundwater, (iii) epikarst hydrodynamics, and (iv) groundwater hydrodynamics by distribution functions that are applied to a set of $N$ model compartments. This allows the simulation of variably dynamic pathways of water and solutes through the karst system. Solute transport simulations within the model follow the assumption of instantaneous and complete mixing within each storage (soil, epikarst, groundwater) and each of the $N$ model compartments (Fig. 3). In the particular case of $\mathrm{NO}_{3}^{-}$, this implies neglecting plant uptake and release processes, which were found to be important in more humid regions (Hartmann et al., 2016) but it was found a valid assumption at Mediterranean regions such as our study site (Hartmann et al., 2013b, 2014b). The detailed equations of the model are in the appendix and a list of all model parameters including their description are provided in Table 2.

\subsection{Parameter estimation for the distinctive flow states and different observation types}

The low resolution of observed discharge and hydrochemistry as well as the complex karstic setting of the study site creates a rather uncertain environment for modelling. For that reason, a traditional multi-objective parameter estimation was omitted as in previous studies (Hartmann et al., 2013b, 2016). Instead, a parameter estimation scheme

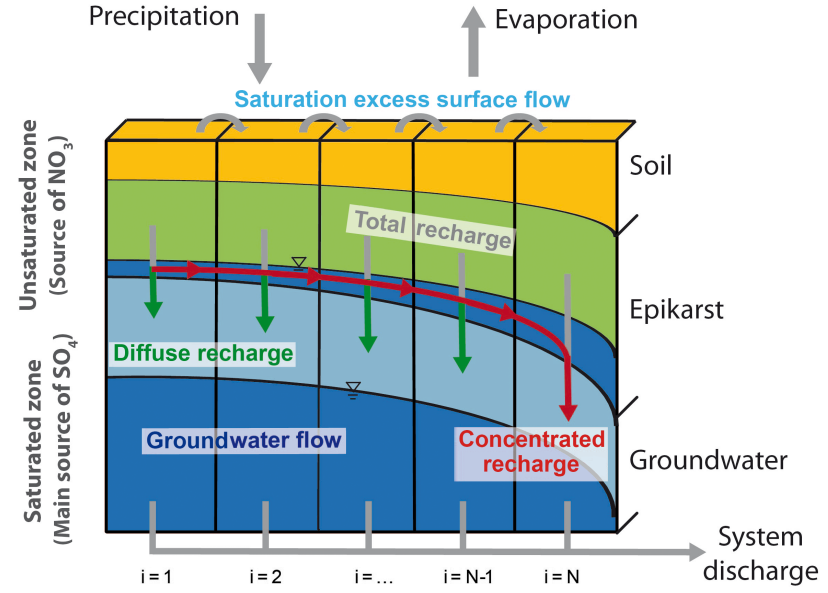

Figure 3. Schematic representation of the VarKarst model structure (modified from Hartmann et al., 2013a).

considering "soft rules" was used to confine a large uniformly sampled set of model parameters therefore explicitly allowing for some uncertainty to remain but to be quantified. A similar approach was already applied successfully in the frame of a large-scale karst groundwater recharge study (Hartmann et al., 2015, 2017).

As a measure of performance, the Kling-Gupta efficiency KGE (Gupta et al., 2009) is used. It is defined to show numbers approaching 1 for the best simulations:

$\mathrm{KGE}=1-\sqrt{(r-1)^{2}+(\alpha-1)^{2}+(\beta-1)^{2}}$,

with

$\alpha=\frac{\sigma_{\mathrm{S}}}{\sigma_{\mathrm{O}}}$ and $\beta=\frac{\mu_{\mathrm{S}}}{\mu_{\mathrm{O}}}$.

$r$ expresses the linear correlation coefficient between simulations and observations, while $\mu_{\mathrm{S}} / \mu_{\mathrm{O}}$ and $\sigma_{\mathrm{S}} / \sigma_{\mathrm{O}}$ are defined as the mean and standard deviation of simulations and observations, respectively. Consequently, $\alpha$ expresses the similarity of simulated and observed variability, while $\beta$ quantifies the bias between them. For the calculation of KGE, only 
time steps for which observations are available are considered. Hence, the KGE values will only express the model performance to reflect the discharge, $\mathrm{NO}_{3}^{-}$, and $\mathrm{SO}_{4}^{2-}$ observations that were sampled in a 7- to 8-day temporal resolution (Table 1) even though the model runs on a daily time step.

For parameter estimation, an initial sample of 500000 parameter sets was created from predefined ranges (Table 2) that were chosen by prior knowledge and previous model experiences in the same region (Hartmann et al., 2013b, 2014b). A 4-year warm-up period was set up and the model was run 500000 times with the initial parameter sample. Using the observed time series, the Kling-Gupta efficiency was calculated for each of the simulation runs: $\mathrm{KGE}_{Q}$ (groundwater discharge), $\mathrm{KGE}_{\mathrm{NO}_{3}}\left(\mathrm{NO}_{3}^{-}\right.$concentrations) and $\mathrm{KGE}_{\mathrm{SO}_{4}}\left(\mathrm{SO}_{4}^{2-}\right.$ concentrations). Similar to Choi and Beven (2007) "soft rules" were used to reduce the initial sample of parameters in four steps:

- All parameter sets from the initial sample with $\mathrm{KGE}_{Q}<0.2$ were discarded.

- All parameter sets from the initial sample with $\mathrm{KGE}_{\mathrm{NO}_{3}}<0.2$ were discarded.

- All parameter sets from the initial sample with $\mathrm{KGE}_{\mathrm{SO}_{4}}<0.2$ were discarded.

- All parameter sets from the initial sample with $\mathrm{KGE}_{Q}$, $\mathrm{KGE}_{\mathrm{NO}_{3}}$, and $\mathrm{KGE}_{\mathrm{SO}_{4}}<0.2$ at the same time were discarded.

The threshold value of 0.2 was found by preliminary analysis. Its rather low value is meant to take into account that the simulation is exposed to various sources of uncertainty including uncertainties in the model input (observation of climate variables and their application to the entire recharge area), model structure uncertainty (representation of karst processes by conceptual mathematical formulations in a semi-distributed way), and the uncertainty of observations (discharge measurement and hydrochemical analysis, as well as their low temporal resolution).

The application of the soft rules is repeated four times for observations falling into the unsaturated flow state, the saturated flow state, the combined unsaturated and saturated flow state and into the entire time period including the hydrodynamic state defined by the influence of the Turón river flow on groundwater discharge. For each of these time periods the four soft rules will result in a reduction in the initial sample, and the prior ranges of the model parameters will experience a confinement (Hartmann et al., 2015).

\subsection{Evaluation of information content and simulation uncertainty for the different flow states and different observation types}

In this study, the strength of this confinement is used to assess the information content of the set of observations during the different flow states. The strength of the confinement is quantified by the reduction in the distance between the 25 th and 75th percentiles of each model parameter after the confinement through the soft rules. For instance, parameter $c_{\mathrm{SO}_{4}}$ (Table 2) has the prior range of $0-100 \mathrm{mg} \mathrm{L}^{-1}$. Consequently, the uniform sampling strategy for the initial sample will result in values close to 25 and $75 \mathrm{mg} \mathrm{L}^{-1}$ for the 25 th and 75 th percentiles, respectively. Applying one of the soft rules may now result in values of 10 and $30 \mathrm{mg} \mathrm{L}^{-1}$ for the 25 th and 75 th percentiles, respectively. Hence, the reduction in the distance between the 25 th and 75 th percentiles is $50-20 \mathrm{mg} \mathrm{L}^{-1}$, i.e. a reduction of $60 \%$ took place. In this example case, we would find that the observations applied through the selected soft rule provided useful information to estimate this parameter. Applying this procedure for each of the four soft rules and the four time series defined by the flow states, we can assess how (1) the different types of observations (discharge, $\mathrm{NO}_{3}^{-}$ and $\mathrm{SO}_{4}^{2-}$ ) contribute to parameter identification, and (2) the focus on particular time periods and flow stages strengthens or weakens the confinement of the model parameters.

Particular attention is given to the comparison of the entire time period, including the times when the spring is influenced by the river, with the time periods when only the unsaturated zone and the saturated zone control the discharge of the spring. It is expected that this time period contains disinformative information for parameter estimation as the VarKarst model does not take into account the river's influence. The reduction between the 25 th and 75 th percentiles of the model parameters is used after applying the fourth soft rule (Sect. 3.3) of the combined unsaturated and saturated flow state, and the entire time period including the period that is influenced by the river to understand the impact of the disinformative information on parameter identification. In a last step, the simulation uncertainty is quantified for the two time periods by plotting the simulations of the parameter sets that remained after the fourth soft rule was applied to the two observation time series. After including the disinformative time period, a greater simulation uncertainty is expected.

\section{Results}

\subsection{Parameter estimation for the different flow states and different observation types}

Different reductions of the initial sample are found by the different soft rules and during the different flow states (Fig. 4). The reduction by discharge $\left(\operatorname{KGE}_{Q} \geq 0.2\right)$ varies among the different flow states but remains rather limited. The same is seen for the individual use of the hydrochemical information $\left(\mathrm{KGE}_{\mathrm{NO}_{3}} \geq 0.2\right.$ or $\left.\mathrm{KGE}_{\mathrm{SO}_{4}} \geq 0.2\right)$. However, using the combination of all soft rules (all KGE $\geq 0.2$ ), a significant reduction in the initial sample is obtained for all flow states. This is most evident for the combined unsaturated and saturated state. The weakest reduction in the initial sample for all soft 
Table 2. Description of model parameters, ranges for parameters estimation and average values found for the combined unsaturated and saturated flow states, and the entire time period including the disinformative period of river influence.

\begin{tabular}{|c|c|c|c|c|c|c|}
\hline \multirow[t]{2}{*}{ Parameter } & \multirow[t]{2}{*}{ Description } & \multirow[t]{2}{*}{ Unit } & \multicolumn{2}{|c|}{ Parameter ranges } & \multirow{2}{*}{$\begin{array}{r}\text { Combined unsat. } \\
\text { and sat. states } \\
\text { mean* }\end{array}$} & \multirow{2}{*}{$\begin{array}{r}\begin{array}{r}\text { Al } \\
\text { states }\end{array} \\
\text { mean* }^{*}\end{array}$} \\
\hline & & & lower & upper & & \\
\hline A & recharge area & $\mathrm{km}^{2}$ & 30 & 80 & 55.5 & 57.5 \\
\hline$V_{\mathrm{S}}$ & mean soil storage capacity & $\mathrm{mm}$ & 0 & 250 & 159.9 & 174.1 \\
\hline$V_{\mathrm{E}}$ & mean epikarst storage capacity & $\mathrm{mm}$ & 0 & 250 & 23.5 & 75.8 \\
\hline$a_{\mathrm{SE}}$ & soil/epikarst depth variability constant & - & 0 & 3 & 0.6 & 1.8 \\
\hline$K_{\mathrm{E}}$ & epikarst mean storage coefficient & $d^{-1}$ & 15 & 65 & 49.4 & 43.4 \\
\hline$a_{f}$ & recharge separation variability constant & - & 0 & 3 & 1.4 & 1.3 \\
\hline$K_{\mathrm{C}}$ & conduit storage coefficient & $d^{-1}$ & 1 & 25 & 5.7 & 12.4 \\
\hline$a_{\mathrm{GW}}$ & groundwater variability constant & - & 0 & 3 & 1.8 & 1.3 \\
\hline$c_{\mathrm{SO}_{4}}$ & mean equilibrium concentration of $\mathrm{SO}_{4}^{2-}$ & $\mathrm{mg} \mathrm{L}^{-1}$ & 0 & 100 & 16.6 & 22.0 \\
\hline$a_{\mathrm{SO}_{4}}$ & $\mathrm{SO}_{4}^{2-}$ variability constant & - & 0 & 3 & 0.6 & 1.4 \\
\hline $\mathrm{KGE}_{Q}$ & performance concerning discharge & - & 0 & 1 & 0.37 & 0.36 \\
\hline $\mathrm{KGE}_{\mathrm{NO}_{3}}^{2}$ & performance concerning $\mathrm{NO}_{3}^{-}$ & - & 0 & 1 & 0.47 & 0.32 \\
\hline $\mathrm{KGE}_{\mathrm{SO}_{4}}$ & performance concerning $\mathrm{SO}_{4}^{2-}$ & - & 0 & 1 & 0.58 & 0.40 \\
\hline
\end{tabular}

* variability of model parameters shown in Fig. 5.

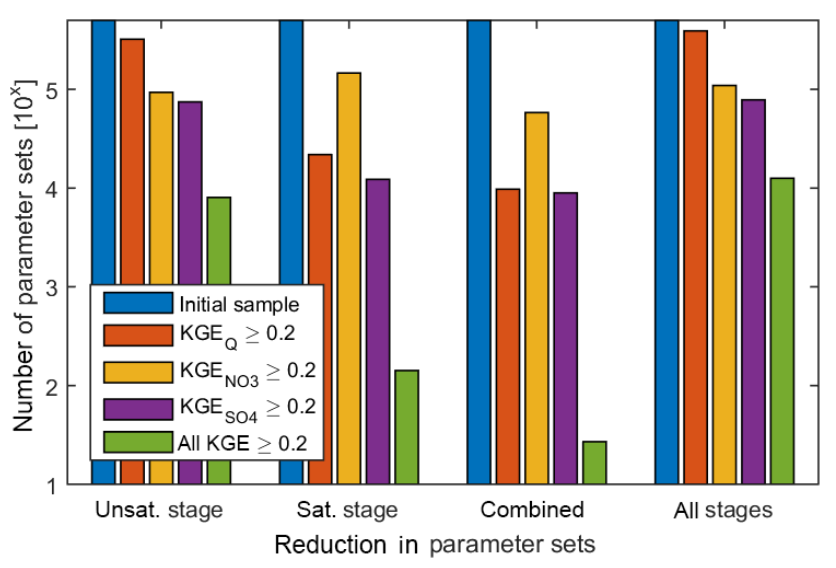

Figure 4. Reduction in the initial sample by the four soft rules for the unsaturated state, saturated state, combined saturated and saturated states, and all system states.

rules is found for the consideration of all stages including the disinformative time period influenced by the river.

The influence of the soft rules during the different flow states varies for all model parameters (Fig. 5). The reduction in the initial sample by discharge $\left(\mathrm{KGE}_{Q} \geq 0.2\right)$ alters the uniform distribution of the initial sample for the different flow states, mostly for the parameters $A, V_{\mathrm{E}}$, and $K_{\mathrm{C}}$. These changes are most prominent in the unsaturated state $(A)$, the saturated state $\left(V_{\mathrm{E}}\right.$ and $\left.K_{\mathrm{C}}\right)$, and the combined unsaturated and saturated states $\left(A, V_{\mathrm{E}}\right.$, and $\left.K_{\mathrm{C}}\right)$. Using $\mathrm{NO}_{3}^{-}$for the reduction $\left(\mathrm{KGE}_{\mathrm{NO}_{3}} \geq 0.2\right)$, the parameters $V_{\mathrm{S}}, V_{\mathrm{E}}$, and $a_{\mathrm{SE}}$ experience the strongest change in their initial distribution. This change is most pronounced at the unsaturated state and the combined unsaturated and saturated states. The reduction by the observations of $\mathrm{SO}_{4}^{2-}$ concentrations $\left(\mathrm{KGE}_{4} \geq 0.2\right)$ mostly affects the model parameters $c_{\mathrm{SO}_{4}}$ and $a_{\mathrm{SO}_{4}}$, but also find a strong impact on $a_{\mathrm{SE}}$, mainly at the saturated state and the combined unsaturated and saturated state. Finally applying all information in the fourth soft rule (all KGE $\geq 0.2$ ), we find again an alteration of the model parameters that were affected by soft rules $1-3\left(A, V_{\mathrm{E}}, V_{\mathrm{S}}, a_{\mathrm{SE}}, K_{\mathrm{C}}, c_{\mathrm{SO}_{4}}\right.$, and $\left.a_{\mathrm{SO}_{4}}\right)$ and, additionally, a moderate alteration of $V_{\mathrm{E}}$ and $a_{f}$. This is most notable at the combined unsaturated and saturated states; using all states including the disinformative period that is influenced by the river the alterations are generally less pronounced.

\subsection{Evaluation of information content and simulation uncertainty for the distinctive flow states and different observation types}

Using the change in distance between the 25th and 75th percentiles of each model parameter for the different soft rules and the different flow states we are able to quantify the information content of the available observations (Fig. 6). We find that discharge $\left(\mathrm{KGE}_{Q} \geq 0.2\right)$ and $\mathrm{SO}_{4}^{2-}\left(\mathrm{KGE}_{\mathrm{SO}_{4}} \geq\right.$ 0.2 ) provide most information during the saturated flow state, while $\mathrm{NO}_{3}^{-}$reduces the distance between the two percentiles most during the unsaturated stage. The state that uses all information including the disinformative time period of river influence shows generally the weakest reduction between the 25th and 75th percentiles as already indicated by Fig. 4 .

Again the most evident changes in model parameter distributions are found for the combined unsaturated and saturated states: here, we see that observed discharge $\left(\mathrm{KGE}_{Q} \geq 0.2\right)$ 


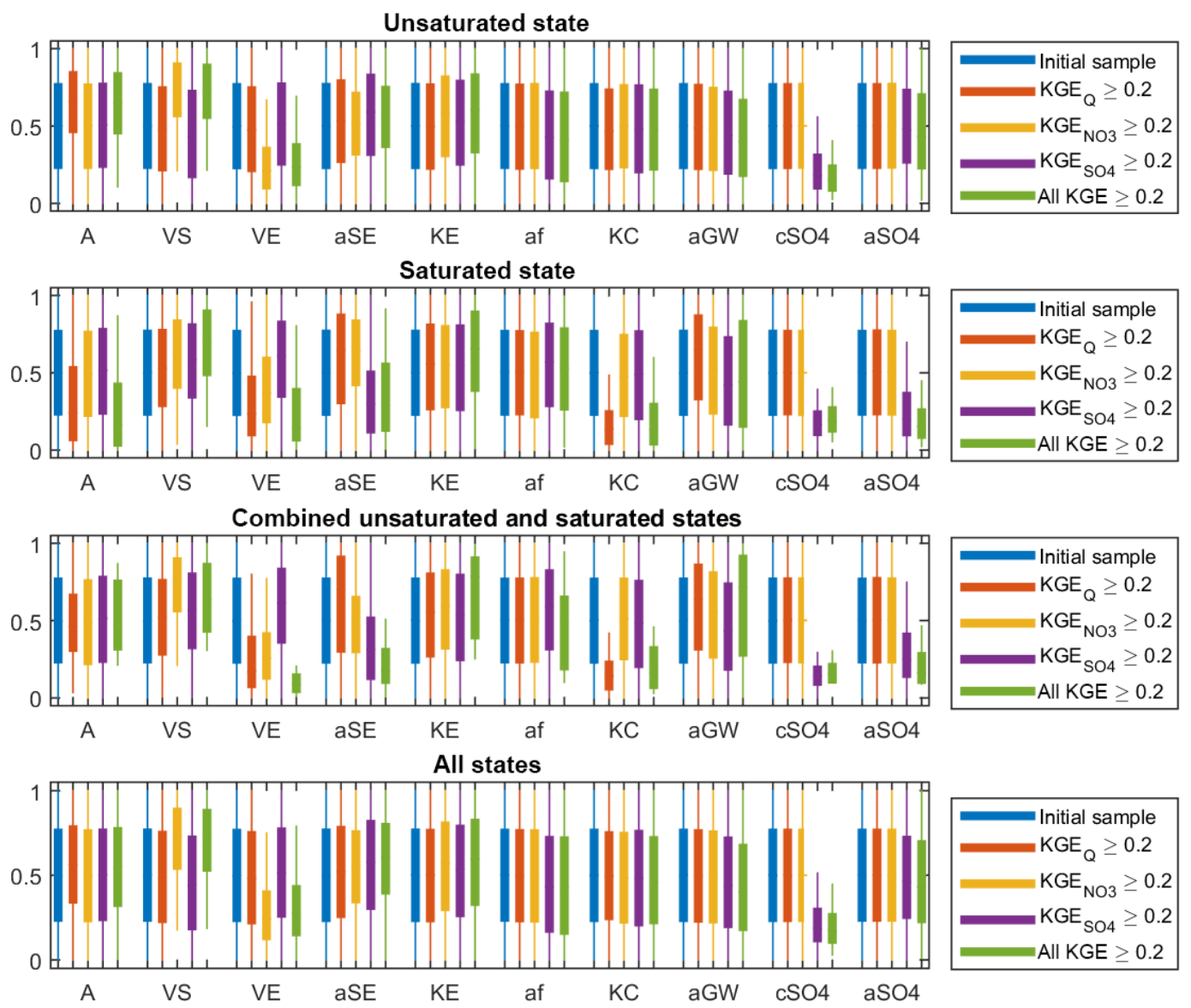

Figure 5. Distribution of model parameters (normalized by their ranges) after applying the four soft rules for the unsaturated, saturated, combined unsaturated and saturated, and all stages.

provides the most information on the parameter $K_{\mathrm{C}}$, but the change in distance for the parameters $A$ and $V_{\mathrm{E}}$ is still considerable. This is most evident in the combined unsaturated and saturated states. We find a more balanced distribution of information on the altered parameters when regarding the reduction obtained by $\mathrm{NO}_{3}^{-}\left(\mathrm{KGE}_{\mathrm{NO}_{3}} \geq 0.2\right)$. Here, the change in distances is considerable (but similar) for $V_{\mathrm{S}}, V_{\mathrm{E}}$, and $a_{\mathrm{SE}}$. For $\mathrm{SO}_{4}^{2-}\left(\mathrm{KGE}_{4} \geq 0.2\right)$, the alteration mostly affects $c_{\mathrm{SO}_{4}}$, followed by a considerable alteration in $a_{\mathrm{SO}_{4}}$ and a moderate change in $a_{\mathrm{SE}}$. Using all information to confine the initial sample (all KGE $\geq 0.2$ ) shows that the combined use of discharge, $\mathrm{NO}_{3}^{-}$and $\mathrm{SO}_{4}^{2-}$ observations provide the most information on $V_{\mathrm{E}}, a_{\mathrm{SE}}, K_{\mathrm{C}}, c_{\mathrm{SO}_{4}}$, and $a_{\mathrm{SO}_{4}}$. Still, considerable information is provided for $A, V_{\mathrm{S}}$, and $a_{f}$. However, no reduction in the distance between the 25 th and 75 th percentiles is found for $V_{\mathrm{E}}$, and even a widening takes place for $a_{\mathrm{GW}}$.

The proceeding analysis indicates that most information to identify the largest number of model parameters is provided by the combined unsaturated and saturated flow states using discharge, $\mathrm{NO}_{3}^{-}$, and $\mathrm{SO}_{4}^{2-}$ observations. It further reveals that using the entire time period, using discharge, $\mathrm{NO}_{3}^{-}$, and $\mathrm{SO}_{4}^{2-}$ observations and including the period that is influenced by the river, provided the least information; only 5 ( $A$, $V_{\mathrm{S}}, V_{\mathrm{E}}, a_{\mathrm{SE}}$, and $\left.c_{\mathrm{SO}_{4}}\right)$ of the 10 model parameters show a detectable reduction in the two flow percentiles (Fig. 6, bottom).

The final averages of the estimated parameters (after applying the 4th soft rule; Table 2) of the combined unsaturated and saturated flow states, and the state that uses the entire set of observations are similar for the parameters $A, V_{\mathrm{S}}$, and $c_{\mathrm{SO}_{4}}$, while there is a strong difference for $V_{\mathrm{E}}$ and $a_{\mathrm{SE}}$. Further comparing the resulting simulation uncertainty (Fig. 7), we find that the final parameter sets that were found using the entire observed time series, including the disinformative river-influenced time period, results in a larger simulation uncertainty than the final parameter sample that used only the combined unsaturated and saturated flow states for parameter estimation. 

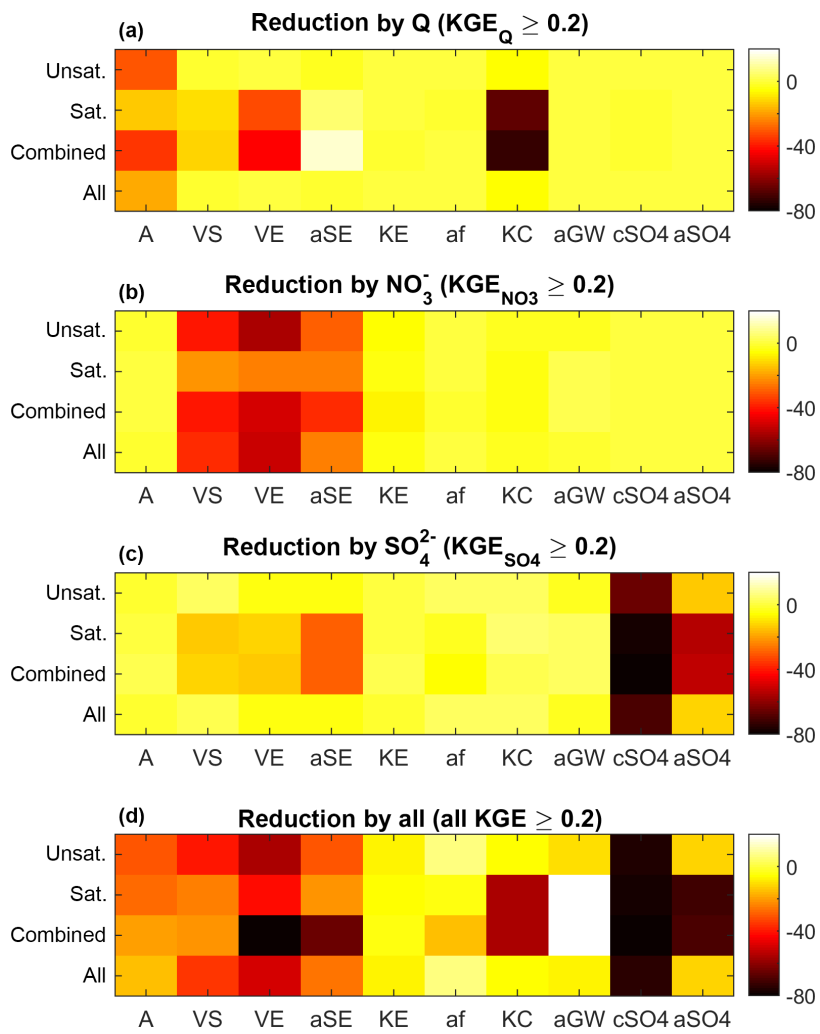

Figure 6. Change in distance between the 25 th and 75 th percentiles of each model parameter when the different soft rules are applied (top to bottom) for the four flow states.

\section{Discussion}

\subsection{Application of the soft rules during the different flow states}

The application of the four soft rules results in a general reduction in the initial sample for all flow states (Fig. 4). A weak reduction for all four flow states takes place when only discharge observations are applied to confine the sample. Previous research with lumped model calibration showed that the information content of discharge observations usually suffices to calibrate 5-6 parameters (Jakeman and Hornberger, 1993; Wheater et al., 1986; Ye et al., 1997); more parameters often lead to over parameterization (Perrin et al., 2003) and equifinality (Beven, 2006). Hence, the small reduction in the VarKarst initial parameter sample may be due to the large number of model parameters (Table 2) within the VarKarst model. The same behaviour of a weak decrease in the initial parameter sample is found when the hydrochemical observations are used individually (soft rules 2 and 3 ). The weakest reduction in the initial parameter sample among all four flow states is found for the entire time period that includes the periods of river influence (see discussion in Sect. 5.2).

When soft rule 4 (all KGE $\geq 0.2$ ) is applied, we find the strongest reduction in the initial sample across all of the four flow states. This means that the combined information of discharge, $\mathrm{NO}_{3}^{-}$, and $\mathrm{SO}_{4}^{2-}$ observations provides the most information to reduce the initial sample of model parameters. Previous research already showed that hydrochemical information can reduce parameter uncertainty (Kuczera and Mroczkowski, 1998; Rimmer and Hartmann, 2014; Son and Sivapalan, 2007). In this study, a similar reduction in parameter uncertainty could be observed (Fig. 5). Depending on the applied soft rule and the considered flow states, the initially uniform distributions of the model parameters are altered differently. Some model parameter distributions change their mean without much change in the shape of their distribution (same distance between 25th and 75th percentiles); some of them show a more confined distribution when the soft rules are applied.

\subsection{Information provided by discharge and hydrochemistry during the different flow states}

The differences in the reduction across the model parameters reveals the influence of different types of observations that were used for parameter estimation. We find that the reductions of the distance between the 25th and 75th percentiles is most pronounced during the saturated stage for the discharge observations (Fig. 6). This indicates that discharge provides the most information during the recession period. Information about hydrodynamic parameters $A, V_{\mathrm{E}}$, and $K_{\mathrm{C}}$ is derived directly from the discharge observations. This makes sense because hydrodynamic changes in the main discharge area of the Sierra Blanquilla aquifer reflect the hydraulic pressure transference from the unsaturated zone to the saturated zone of the system. Similar results were found by Wagener et al. (2003) when they applied dynamic identifiability analysis to a lumped rainfall-runoff model using only discharge data.

They also found that the parameters, which control the unsaturated zone and fast flow components of their model, are most identifiable during and just after the rainfall-runoff events. Our results indicate a similar behaviour by showing the strongest reduction in the distance between the 25 th and 75th percentiles for the unsaturated zone parameters during the unsaturated flow state using the $\mathrm{NO}_{3}^{-}$observations (parameters $V_{\mathrm{S}}, V_{\mathrm{E}}$, and $a_{\mathrm{SE}}$ ). This is in accordance with Reusser and Zehe (2011) who showed that model parameters that control the recession period are most sensitive during the recession period with a time dynamic resection and cluster analysis using discharge information. $\mathrm{NO}_{3}^{-}$has been used almost as an ideal tracer to determine infiltration processes through the soil and epikarst in the shallower aquifer zones (Hunkeler and Mudry, 2007; Mudarra et al., 2014). Thus, $\mathrm{NO}_{3}^{-}$observations contribute strongly to the identification of surface and evapotranspiration processes during the unsaturated flow state. This can be explained by the relative 


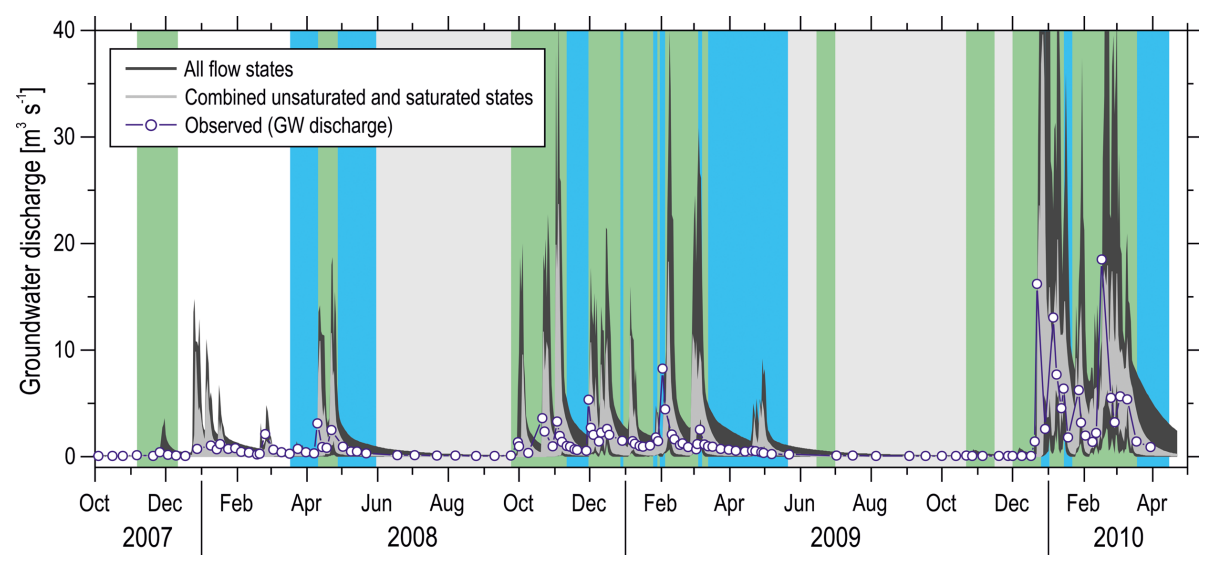

Figure 7. Observed discharge and the simulation uncertainty of the final parameter sample (all KGE $\geq 0.2$ ) of the combined unsaturated and saturated flow states and the all flow states including the disinformative period of river influence. Background colours representing flow states match those in Fig. 2.

stability of $\mathrm{NO}_{3}^{-}$dynamics within the karst system under oxidizing conditions (Mudarra et al., 2014), which favours its preservation from surface to the spring.

$\mathrm{SO}_{4}^{2-}$ provided most information on the parameters $c_{\mathrm{SO}_{4}}$, $a_{\mathrm{SO}_{4}}$, and $a_{\mathrm{SE}}$ during the saturated state. This makes sense as $\mathrm{SO}_{4}^{2-}$ is stored within the saturated zone of the system where groundwater is in touch with gypsum-bearing geological formations (Triassic clays with evaporites), which are found in contact with deeper aquifer compartments. $\mathrm{SO}_{4}^{2-}$ time series provide more information about the unsaturated zone/epikarst drainage during the saturated flow stage. Such findings mean that the high chemical contrast observed in $\mathrm{SO}_{4}^{2-}$ concentrations of fresh (recently infiltrated) and old (stored) groundwater is useful to assess the relative importance of unsaturated flow and saturated flow during the saturated flow stage (Barberá and Andreo, 2015; Mudarra et al., 2011).

The highest number of identifiable parameters is found when all information (discharge, $\mathrm{NO}_{3}^{-}$, and $\mathrm{SO}_{4}^{2-}$ observations) is combined and estimated during the combined unsaturated and saturated flow stages (Fig. 6). In addition to the parameters that showed an increase in identifiability at the individual stages $\left(A, V_{\mathrm{E}}, K_{\mathrm{C}}, V_{\mathrm{S}}, K_{\mathrm{E}}, a_{\mathrm{SE}}, c_{\mathrm{SO}_{4}}\right.$, and $a_{\mathrm{SO}_{4}}$ ), we also see an increased identifiability of the parameter $a_{f}$, most probably due to parameter interactions (Pianosi et al., 2016). Only $a_{\mathrm{GW}}$ and $K_{\mathrm{E}}$ remain with low identifiability, which may be due to structural limitations of the model structure (Clark et al., 2008) or due to parameter interactions that are not explicitly considered in our approach. In fact, a lower identifiability of $V_{\mathrm{E}}$ in favour of a high identifiability of $V_{\mathrm{E}}$ was found in a previous study with a similar version of the model (Hartmann et al., 2015). Compared to that, using all information during the entire time period, including the disinformative period, only five of the model parameters show a visible decrease in the distance between the 25th and 75 th percentiles of their distribution. Hence, the inclusion of the disinformative period led to an increase in posterior parameter uncertainty compared to using only the informative time periods represented by the unsaturated and saturated states. This was also shown by Beven and Westerberg (2011) or Beven et al. (2011), when they considered the impact of disinformative discharge events.

The impact of the disinformative time period on the precision of the observations is clearly visible in Fig. 7. Since the model has to compensate for structural errors, i.e. the missing representation of the influence of the river on the discharge of the karst spring, it is forced to allow for a wider range of parameter combinations to account for the simulation errors. Using only the unsaturated and saturated states allows for a much better confinement of model parameters and therefore a much smaller simulation uncertainty, although showing some deviations during the periods when the fiver affects the flow system of the spring (blue shaded areas in Fig. 7). Hence, similar to Kauffeldt et al. (2013), our study shows that a proper pre-analysis of the information content of observations for model parameter estimation (Sect. 2.2) allows for excluding disinformative information to reduce model parameter and simulation uncertainty.

\subsection{Limits and transferability of the approach}

The analysis of variations in the groundwater component in the Turón river flow has permitted us to determine the timing, duration, and magnitude of the global hydrodynamic aquifer responses under influenced hydrological conditions, as well as to assess the discharge thresholds from which different compartments of the system activate (i.e. flooding of relict conduit networks; Barberá and Andreo, 2015). However, a more accurate decomposition of flow components from the study of spring hydrographs has not been possible due to the relatively low resolution of discharge time series (Table 1). Even though the chemical signature of groundwater 
that drains the different aquifer zones (unsaturated zone and saturated zone), and that is affected by the Turón river, can be estimated using EC (Fig. 2), it is rather based on subjective interpretation. However, it can be argued that the previous knowledge based on the accurate interpretation of the El Burgo spring chemographs has permitted a realistic flow decomposition from EC time series as our results show a clear difference in estimated parameter distributions and resulting simulation uncertainty using the unsaturated and saturated flow states and the entire time period including the disinformative data. A more precise distinction between the states is only possible if specific chemical indicators are available to better constrain the differentiation of flow states contributing to the El Burgo spring discharge, which was not possible within the frame of this study. But even though due to subjectivity, the identification of time periods or data sets that contain disinformative contributions to parameter estimation is a useful way to reduce the simulation uncertainty of hydrological models. Building on previous research on disinformative data that focussed on disinformative discharge information, our approach provides a systematic procedure that also includes hydrochemical observations to identify disinformative periods and to improve parameter estimation of models for complex hydrological systems. Another limitation of our research is the low resolution of the discharge and hydrochemical observations (7-8 days). Although our approach took into account this weakness by the soft rules allowing for remaining uncertainty after the reduction in our 500000 parameter sets, we believe that a higher resolution of the observations (preferably 1 day) would have resulted in a more pronounced reduction in the initial sample and consequently to a lower remaining uncertainty.

\section{Conclusions}

In this research, a new approach to estimate the information content of water quality data and the value of identifying most informative periods for model parameter estimation has been proposed. Using soft rules to include discharge, $\mathrm{NO}_{3}^{-}$ and $\mathrm{SO}_{4}^{2-}$ observations into the parameter estimation procedure, we were able to reduce an initial sample of 500000 parameter sets during predefined flow states; one being a known period of disinformative data. Comparing the distributions of the initial and reduced parameter sets, we were able to quantify the information contained in our observations to identify the parameters of our simulation model.
We found that the information content of the observations varies for the different states that we considered. $\mathrm{NO}_{3}^{-}$provided most of its information when the unsaturated zone processes dominate the discharge behaviour of the spring. During the time when the saturated zone controls the outflow behaviour, $\mathrm{SO}_{4}^{2-}$ and discharge observations provide the best information to identify the model parameters. Including the disinformative period, the information content of all data generally decreases, as well as the uncertainty in simulations increases. We finally show that the combination of saturated and unsaturated flow states provides the most precise information about the model parameters. Due to parameter interactions, even model parameters that were not identifiable during the unsaturated or saturated flow state alone became identifiable. As a result, the simulation uncertainty is significantly reduced compared to the simulations obtained by the entire time series of observations that include the disinformative data.

Even though exemplified at a particular karst spring in southern Spain, our approach is easily transferrable to other modelling studies that want to use water quality data for the identification of disinformative periods and for the estimation of model parameters. Our results add to previous findings on the value of removing disinformative data from model parameter estimation to reduce simulation uncertainty. Furthermore our results can help building a better communication between experimental hydrologists and modelers (Hartmann, 2016; Seibert and McDonnell, 2002) as hydrochemical data is often used for system characterization. Our study showed that $\mathrm{NO}_{3}^{-}$and $\mathrm{SO}_{4}^{2-}$, often used for understanding the unsaturated and saturated zone processes, also help to identify the corresponding process parameters in our model. Further research should, therefore, include the evaluation of other hydrochemical variables that can be attributed to particular hydrological processes, and their value to identify the corresponding processes in process-based simulation models. Also, a further disaggregation of the Kling-Gupta efficiency into its components, correlation, bias, and variability, contains high promise for further advancement of our approach.

Data availability. The data used in this study can be requested from the Department of Geology and the Centre of Hydrogeology of the University of Malaga (CEHIUMA), Malaga 29071, Spain. 


\section{Appendix A}

The parameter $V_{\text {mean,S }}(\mathrm{mm})$ and the distribution coefficient $a_{\text {SE }}(-)$ control the variability in soil depths over the $N$ model compartments. Using them, the soil storage capacity $V_{\mathrm{S}, i}$ $(\mathrm{mm})$ for every compartment $i$ is defined by the following:

$V_{\mathrm{S}, i}=V_{\mathrm{max}, \mathrm{S}} \cdot\left(\frac{i}{N}\right)^{a_{\mathrm{SE}}}$.

$V_{\max , \mathrm{S}}(\mathrm{mm})$ represents the maximum soil storage capacity and is derived from $V_{\mathrm{S}}$ by the following:

$$
\begin{gathered}
\int_{0}^{i_{1 / 2}} V_{\max , \mathrm{S}}\left(\frac{x}{N}\right)^{a_{\mathrm{SE}}} \mathrm{d} x=\frac{\int_{0}^{N} V_{\max , \mathrm{S}}\left(\frac{x}{N}\right)^{a_{\mathrm{SE}}} \mathrm{d} x}{2} ; V_{\mathrm{S}}=V_{\max , \mathrm{S}}\left(\frac{i_{1 / 2}}{N}\right)^{a_{\mathrm{SE}}}, \\
V_{\max , \mathrm{S}}=V_{\mathrm{S}} \cdot 2^{\left(\frac{a_{\mathrm{SE}}}{a_{\mathrm{SE}}+1}\right)}
\end{gathered}
$$

where the compartment at which the volumes on the left equal the volumes on the right is found at $i_{1 / 2}$. The same distribution coefficient $a_{\mathrm{SE}}$ is used to derive the epikarst storage distribution by the mean epikarst depth $V_{\mathrm{E}}(\mathrm{mm})$ (derivation of $V_{\max , \mathrm{E}}$ likewise to $V_{\max , \mathrm{S}}$ in Eq. 4)

$$
V_{\mathrm{E}, i}=V_{\mathrm{max}, \mathrm{E}} \cdot\left(\frac{i}{N}\right)^{a_{\mathrm{SE}}} .
$$

Actual evapotranspiration from each soil compartment $E_{\text {act }, i}$ is calculated by

$$
\begin{aligned}
& E_{\mathrm{act}, i}(t)=E_{\mathrm{pot}}(t) \\
& \quad \cdot \frac{\min \left[V_{\mathrm{Soil}, i}(t)+P(t)+Q_{\text {Surface }, i}(t), V_{\mathrm{S}, i}\right]}{V_{\mathrm{S}, i}} .
\end{aligned}
$$

Potential evapotranspiration $E_{\text {pot }}(\mathrm{mm})$ is found by the Thornthwaite equation (Thornthwaite, 1948) and $Q_{\text {surface, } i}$ $(\mathrm{mm})$ is the surface inflow that originates from compartment $i-1$ (see Eq. 11). $V_{\text {Soil }, i}(\mathrm{~mm})$ is the volume of water stored in the soil at time step $t$. Recharge from the soil to the epikarst $R_{\mathrm{Epi}, i}(\mathrm{~mm})$ is found by water balance

$$
\begin{aligned}
& R_{\mathrm{Epi}, i}(t)=Q_{\mathrm{inf}}(t)+\max \\
& \quad\left[V_{\mathrm{Soil}, i}(t)+P(t)+Q_{\text {Surface }, i}(t)-E_{\mathrm{act}, i}(t)-V_{\mathrm{S}, i}, 0\right],
\end{aligned}
$$

with $Q_{\text {inf }}(t)$ being the river infiltration (Eq. 5). The epikarst storage coefficient $K_{\mathrm{E}, i}$ (d) controls the outflow from the epikarst

$$
Q_{\mathrm{Epi}, i}(t)=\frac{\min \left[V_{\mathrm{Epi}, i}(t)+R_{\mathrm{Epi}, i}(t), V_{\mathrm{E}, i}\right]}{K_{\mathrm{E}, i}} \cdot \Delta t,
$$

$K_{\mathrm{E}, i}=K_{\max , \mathrm{E}} \cdot\left(\frac{N-i+1}{N}\right)^{a_{\mathrm{SE}}}$.
Here, $V_{\text {Epi, } i}(\mathrm{~mm})$ is the water stored in the epikarst at time step $t$. $K_{\max , \mathrm{E}}$ is found by the mean epikarst storage coefficient $V_{\mathrm{E}}$ and by applying the same distribution coefficient $a_{\mathrm{SE}}$

$$
\begin{gathered}
N \cdot K_{\mathrm{E}}=\int_{0}^{N} K_{\max , \mathrm{E}}\left(\frac{x}{N}\right)^{a_{\mathrm{SE}}} \mathrm{d} x \\
K_{\mathrm{max}, \mathrm{E}}=K_{\mathrm{E}} \cdot\left(a_{\mathrm{SE}}+1\right) .
\end{gathered}
$$

Surface flow to the next model compartment $Q_{\text {Surf }, i+1}(\mathrm{~mm})$ initiates when soil and epikarst storage capacities are exceeded:

$Q_{\mathrm{Surf}, i+1}(t)=\max \left[V_{\mathrm{Epi}, i}(t)+R_{\mathrm{Epi}, i}(t)-V_{\mathrm{E}, i}, 0\right]$.

The vertical percolation from the epikarst is split into diffuse $\left(R_{\mathrm{diff}, i}, \mathrm{~mm}\right)$ and concentrated groundwater recharge $\left(R_{\mathrm{conc}, i}, \mathrm{~mm}\right)$ again by a variable separation factor $f_{\mathrm{C}, i}(-)$ and a distribution coefficient $a_{f}(-)$

$$
\begin{aligned}
& R_{\mathrm{conc}, i}(t)=f_{\mathrm{C}, i} \cdot Q_{\mathrm{Epi}, i}(t), \\
& R_{\mathrm{diff}, i}(t)=\left(1-f_{\mathrm{C}, i}\right) \cdot Q_{\mathrm{Epi}, i}(t), \\
& f_{\mathrm{C}, i}=\left(\frac{i}{N}\right)^{a_{f}} .
\end{aligned}
$$

The diffuse recharge reaches the groundwater compartments $(i=1 \ldots N-1)$ directly below, while concentrated recharge is routed laterally to the conduit system (compartment $i=N$ ). Similar to epikarst storage coefficients, variable groundwater storage coefficients $K_{\mathrm{GW}, i}$ (d) are calculated. The, groundwater contributions of the matrix system $Q_{\mathrm{GW}, i}(\mathrm{~mm})$ in therefore found by the following:

$$
Q_{\mathrm{GW}, i}(t)=\frac{V_{\mathrm{GW}, i}(t)+R_{\mathrm{diff}, i}(t)}{K_{\mathrm{GW}, i}} ; i=1 \ldots N-1,
$$

with

$$
K_{\mathrm{GW}, i}=K_{\mathrm{C}} \cdot\left(\frac{i}{N}\right)^{-a_{\mathrm{GW}}} .
$$

The conduit system discharges from compartment $N$

$Q_{\mathrm{GW}, i}(t)=\frac{V_{\mathrm{GW}, N}(t)+\sum_{i=1}^{N} R_{\mathrm{conc}, i}(t)}{K_{\mathrm{C}}} ; i=N$,

where the conduit storage coefficient is given by $K_{\mathrm{C}}(\mathrm{d})$. The discharge of the main spring $Q_{\text {main }}\left(\mathrm{L} \mathrm{s}^{-1}\right)$ is comprised of the sum of the matrix and the conduit system discharge rescaled to $\mathrm{L} \mathrm{s}^{-1}$ units the recharge area $A\left(\mathrm{~km}^{2}\right)$

$Q_{\text {main }}(t)=\frac{A}{N} \cdot \sum_{i=1}^{N} Q_{\mathrm{GW}, i}(t)$. 
Solute transport within the VarKarst model follows the assumption of complete mixing for every model compartment. Hence, enrichment only takes place due to evaporation and by geogenic dissolution (only $\mathrm{SO}_{4}^{2-}$ ), for which varying equilibrium concentrations are defined according to

$c_{\mathrm{SO}_{4}, i}=c_{\max , \mathrm{SO}_{4}} \cdot\left(\frac{N-i+1}{N}\right)^{a_{\mathrm{SO}_{4}}}$,

where $a_{\mathrm{SO}_{4}}$ is a variability constant and $c_{\mathrm{max}, \mathrm{SO}_{4}}$ is derived from $c_{\mathrm{SO}_{4}}\left(\mathrm{mg} \mathrm{L}^{-1}\right)$ (similar to Eq. 10). 
Competing interests. The authors declare that they have no conflict of interest.

Acknowledgements. This work is a contribution to the projects P06-RNM 2161 of Junta de Andalucía; and CGL2008-06158 BTE, CGL2012-32590, CGL2015-65858-R of DGICYT; and to the Research Group RNM-308 of the Junta de Andalucía. The article processing charge was funded by the German Research Foundation (DFG) and the University of Freiburg in the funding programme Open Access Publishing.

Edited by: Matthias Bernhardt

Reviewed by: Naomi Mazzilli and Arnauld Malard

\section{References}

Aquilina, L., Ladouche, B., Dörfliger, N., and Doerfliger, N.: Water storage and transfer in the epikarst of karstic systems during high flow periods, J. Hydrol., 327, 472-485, 2006.

Bakalowicz, M.: Karst groundwater: a challenge for new resources, Hydrogeol. J., 13, 148-160, https://doi.org/10.1007/s10040-0040402-9, 2005.

Barberá, J. A.: Hydrogeological research in the carbonate aquifers of eastern Serranía de Ronda (Málaga) in Spanish and English, $\mathrm{PhD}$ thesis at the Centre of Hydrogeology of the University of Málaga CEHIUMA (Spain), 2014.

Barberá, J. A. and Andreo, B.: Hydrogeological characterization of two karst springs in southern Spain by hydrochemical data and intrinsic natural fluorescence, in: IAH Selected Papers Groundwater Quality Sustainability, edited by: Maloszewski, P., Witczak, S., and Malina, G., Vol. 17, 281-295, ISBN:978-0-41569841-2, 2012.

Barberá, J. A. and Andreo, B.: Hydrogeological processes in a fluviokarstic area inferred from the analysis of natural hydrogeochemical tracers. The case study of eastern Serranía de Ronda (S Spain), J. Hydrol., 523, 500-514, https://doi.org/10.1016/j.jhydrol.2015.01.080, 2015.

Beven, K. and Westerberg, I.: On red herrings and real herrings: Disinformation and information in hydrological inference, Hydrol. Process., 25, 1676-1680, https://doi.org/10.1002/hyp.7963, 2011.

Beven, K., Smith, P. J., and Wood, A.: On the colour and spin of epistemic error (and what we might do about it), Hydrol. Earth Syst. Sci., 15, 3123-3133, https://doi.org/10.5194/hess-15-31232011, 2011.

Beven, K. J.: A manifesto for the equifinality thesis, J. Hydrol., 320, 18-36, 2006.

Brenner, S., Coxon, G., Howden, N. J. K., Freer, J., and Hartmann, A.: A percentile approach to evaluate simulated groundwater levels and frequencies in a Chalk catchment in Southwest England, Nat. Hazards Earth Syst. Sci. Discuss., https://doi.org/10.5194/nhess-2016-386, in review, 2016.

Charlier, J.-B., Bertrand, C., and Mudry, J.: Conceptual hydrogeological model of flow and transport of dissolved organic carbon in a small Jura karst system, J. Hydrol., 460-461, https://doi.org/10.1016/j.jhydrol.2012.06.043, 2012.
Choi, H. T. and Beven, K.: Multi-period and multi-criteria model conditioning to reduce prediction uncertainty in an application of TOPMODEL within the GLUE framework, J. Hydrol., 332, 316-336, https://doi.org/10.1016/j.jhydrol.2006.07.012, 2007.

Clark, M. P., Slater, A. G., Rupp, D. E., Woods, R. A., Vrugt, J. A., Gupta, H. V, Wagener, T., and Hay, L. E.: Framework for Understanding Structural Errors (FUSE): A modular framework to diagnose differences between hydrological models, Water Resour. Res., 44, W00B02, https://doi.org/10.1029/2007WR006735, 2008.

Cruz-Sanjulián, J. J.: Estudio geológico del sector Cañete la RealTeba-Osuna (Cordillera Bética, región occidental), $\mathrm{PhD}$ thesis, Universidad de Granada, 374 pp., 1974.

Fernández, R.: Investigaciones hidrogeológicas al Norte de Ronda (Málaga), Granada, Simposio del Agua en Andalucía 2, 643658, 1980.

Ford, D. C. and Williams, P. W.: Karst Hydrogeology and Geomorphology, John Wiley \& Sons, Wiley, Chichester, United Kingdom, 567 pp., ISBN:978-0-470-84996-5, 2007.

Ghasemizadeh, R., Hellweger, F., Butscher, C., Padilla, I., Vesper, D., Field, M., and Alshawabkeh, A.: Review: Groundwater flow and transport modeling of karst aquifers, with particular reference to the North Coast Limestone aquifer system of Puerto Rico, Hydrogeol. J., 20, 1441-1461, https://doi.org/10.1007/s10040012-0897-4, 2012.

Goldscheider, N. and Drew, D.: Methods in Karst Hydrogeology, edited by: I. A. of Hydrogeologists, Taylor \& Francis Group, Leiden, NL, ISBN:978-0-415-42873-6, 2007.

Gupta, H. V., Kling, H., Yilmaz, K. K., and Martinez, G. F.: Decomposition of the mean squared error and NSE performance criteria: Implications for improving hydrological modelling, J. Hydrol., 377, 80-91, https://doi.org/10.1016/j.jhydrol.2009.08.003, 2009.

Hartmann, A.: Putting the cat in the box: why our models should consider subsurface heterogeneity at all scales, WIREs Water, https://doi.org/10.1002/wat2.1146, 2016.

Hartmann, A. and Baker, A.: Modelling karst vadose zone hydrology and its relevance for paleoclimate reconstruction, EarthSci. Rev., 1-54, https://doi.org/10.1016/j.earscirev.2017.08.001, 2017.

Hartmann, A., Lange, J., Weiler, M., Arbel, Y., and Greenbaum, N.: A new approach to model the spatial and temporal variability of recharge to karst aquifers, Hydrol. Earth Syst. Sci., 16, 22192231, https://doi.org/10.5194/hess-16-2219-2012, 2012.

Hartmann, A., Weiler, M., Wagener, T., Lange, J., Kralik, M., Humer, F., Mizyed, N., Rimmer, A., Barberá, J. A., Andreo, B., Butscher, C., and Huggenberger, P.: Process-based karst modelling to relate hydrodynamic and hydrochemical characteristics to system properties, Hydrol. Earth Syst. Sci., 17, 3305-3321, https://doi.org/10.5194/hess-17-3305-2013, 2013a.

Hartmann, A., Barberá, J. A., Lange, J., Andreo, B., Weiler, M., Antonio, J., Lange, J., Andreo, B., Weiler, M., Barberá, J. A., Lange, J., Andreo, B., and Weiler, M.: Progress in the hydrologic simulation of time variant recharge areas of karst systems - Exemplified at a karst spring in Southern Spain, Adv. Water Res., 54, 149160, https://doi.org/10.1016/j.advwatres.2013.01.010, 2013b.

Hartmann, A., Goldscheider, N., Wagener, T., Lange, J., and Weiler, M.: Karst water resources in a changing world: Review of hydrological modeling approaches, Rev. Geophys., 52, 218-242, https://doi.org/10.1002/2013rg000443, 2014a. 
Hartmann, A., Mudarra, M., Andreo, B., Marín, A., Wagener, T., and Lange, J.: Modeling spatiotemporal impacts of hydroclimatic extremes on groundwater recharge at a Mediterranean karst aquifer, Water Resour. Res., 50, 6507-6521, https://doi.org/10.1002/2014WR015685, 2014b.

Hartmann, A., Gleeson, T., Rosolem, R., Pianosi, F., Wada, Y., and Wagener, T.: A large-scale simulation model to assess karstic groundwater recharge over Europe and the Mediterranean, Geosci. Model Dev., 8, 1729-1746, https://doi.org/10.5194/gmd8-1729-2015, 2015.

Hartmann, A., Kobler, J., Kralik, M., Dirnböck, T., Humer, F., and Weiler, M.: Model-aided quantification of dissolved carbon and nitrogen release after windthrow disturbance in an Austrian karst system, Biogeosciences, 13, 159-174, https://doi.org/10.5194/bg-13-159-2016, 2016.

Hartmann, A., Gleeson, T., Wada, Y., Wagener, T., Kingdom, U., Sciences, O., and Kingdom, U.: Enhanced groundwater recharge rates and altered recharge sensitivity to climate variability through subsurface heterogeneity, P. Natl. Acad. Sci. USA, 19, EGU2017-12796, https://doi.org/10.1073/pnas.1614941114, 2017.

Hunkeler, D. and Mudry, J.: Hydrochemical tracers, Methods in karst hydrogeology, edited by: Goldscheider, N. and Drew, D., 93-121, Taylor and Francis/Balkema, London, UK, 2007.

Jakeman, A. J. and Hornberger, G. M.: How much complexity is warranted in a rainfall-runoff model?, Water Resour. Res., 29, 2637-2649, 1993.

Kauffeldt, A., Halldin, S., Rodhe, A., Xu, C.-Y., and Westerberg, I. K.: Disinformative data in large-scale hydrological modelling, Hydrol. Earth Syst. Sci., 17, 2845-2857, https://doi.org/10.5194/hess-17-2845-2013, 2013.

Kovacs, A. and Sauter, M.: Modelling karst hydrodynamics, Methods in karst hydrogeology, edited by: Goldscheider, N. and Drew, D., 65-91, Taylor and Francis/Balkema, London, UK, 2007.

Kuczera, G. and Mroczkowski, M.: Assessment of hydrologic parameter uncertainty and the worth of multiresponse data, Water Resour. Res., 34, 1481-1489, 1998.

Labat, D., Ababou, R., and Mangin, A.: Rainfall-runoff relations for karstic springs. Part I: convolution and spectral analyses, J. Hydrol., 238, 123-148, 2000.

Martín-Algarra, A.: Evolución geológica Alpina del contacto entre las Zonas Internas y las Zonas Externas de la Cordillera Bética (Sector Occidental), Universidad de Granada, 1987.

Mazzilli, N., Jourde, H., Jacob, T., Guinot, V., Moigne, N., Boucher, M., Chalikakis, K., Guyard, H., and Legtchenko, A.: On the inclusion of ground-based gravity measurements to the calibration process of a global rainfall-discharge reservoir model: case of the Durzon karst system (Larzac, southern France), Environ. Earth Sci., 68, 1631-1646, https://doi.org/10.1007/s12665-012-1856z, 2012.

Mudarra, M., Andreo, B., and Mudry, J.: Monitoring groundwater in the discharge area of a complex karst aquifer to assess the role of the saturated and unsaturated zones, Environ. Earth Sci., 65, 2321-2336, https://doi.org/10.1007/s12665-011-1032-x, 2011.
Mudarra, M., Andreo, B., Marína, I., Vadillo, I., and Barberá, J. A.: Combined use of natural and artificial tracers to determine the hydrogeological functioning of a karst aquifer: the Villanueva del Rosario system (Andalusia, southern Spain), Hydrogeol. J., 22, 1027-1039, https://doi.org/10.1007/s10040-014-1117-1, 2014.

Oehlmann, S., Geyer, T., Licha, T., and Sauter, M.: Reducing the ambiguity of karst aquifer models by pattern matching of flow and transport on catchment scale, Hydrol. Earth Syst. Sci., 19, 893-912, https://doi.org/10.5194/hess-19-893-2015, 2015.

Perrin, C., Michel, C., and Andréassian, V.: Improvement of a parsimonious model for streamflow simulation, J. Hydrol., 279, 275 289, 2003.

Pianosi, F., Beven, K., Freer, J., Hall, J. W., Rougier, J., Stephenson, D. B., and Wagener, T.: Sensitivity analysis of environmental models: A systematic review with practical workflow, Environ. Model. Softw., 79, 214-232, https://doi.org/10.1016/j.envsoft.2016.02.008, 2016.

Reusser, D. E. and Zehe, E.: Inferring model structural deficits by analyzing temporal dynamics of model performance and parameter sensitivity, Water Resour. Res., 47, https://doi.org/10.1029/2010wr009946, 2011.

Rimmer, A. and Hartmann, A.: Optimal hydrograph separation filter to evaluate transport routines of hydrological models, J. Hydrol., 514, 249-257, https://doi.org/10.1016/j.jhydrol.2014.04.033, 2014.

Sauter, M., Kovács, A., Geyer, T., and Teutsch, G.: Modellierung der Hydraulik von Karstgrundwasserleitern - Eine Übersicht, Grundwasser, 3, 143-156, 2006.

Seibert, J. and McDonnell, J. J.: On the dialog between experimentalist and modeler in catchment hydrology: Use of soft data for multicriteria model calibration, Water Resour. Res., 38, 1241, https://doi.org/10.1029/2001WR000978, 2002.

Son, K. and Sivapalan, M.: Improving model structure and reducing parameter uncertainty in conceptual water balance models through the use of auxiliary data, Water Resour. Res., 43, W01415, https://doi.org/10.1029/2006wr005032, 2007.

Thornthwaite, C. W.: An Approach toward a Rational Classification of Climate, Geogr. Rev., 38, 55-94, https://doi.org/10.2307/210739, 1948.

Wagener, T., McIntyre, N., Lees, M. J., Wheater, H. S., and Gupta, H. V: Towards reduced uncertainty in conceptual rainfall-runoff modelling: dynamic identifiability analysis, Hydrol. Process., 17, 455-476, https://doi.org/10.1002/hyp.1135, 2003.

Wheater, H. S., Bishop, K. H., and Beck, M. B.: The identification of conceptual hydrological models for surface water acidification, Hydrol. Process., 1, 89-109, https://doi.org/10.1002/hyp.3360010109, 1986.

White, W. B. and White, E. L.: Ground water flux distribution between matrix, fractures, and conduits?: constraints on modeling, Speleogenesis and Evolution of Karst Aquifers, 3, 1-6, 2003.

Ye, W., Bates, B. C., Viney, N. R., Sivapalan, M., and Jakeman, A. J.: Performance of conceptual rainfall-runoff models in lowyielding ephemeral catchments, Water Resour. Res., 33, 153166, https://doi.org/10.1029/96wr02840, 1997. 